University of Montana

ScholarWorks at University of Montana

\title{
Tests of Landscape Influence: Nest Predation and Brood Parasitism in Fragmented Ecosystems
}

\author{
J. J. Tewksbury \\ L. Garner \\ S. Garner \\ J. D. Lloyd \\ V. Saab \\ See next page for additional authors
}

Follow this and additional works at: https://scholarworks.umt.edu/wildbio_pubs

Part of the Life Sciences Commons

Let us know how access to this document benefits you.

\section{Recommended Citation}

Tewksbury, J. J.; Garner, L.; Garner, S.; Lloyd, J. D.; Saab, V.; and Martin, Thomas E., "Tests of Landscape Influence: Nest Predation and Brood Parasitism in Fragmented Ecosystems" (2006). Wildlife Biology Faculty Publications. 13.

https://scholarworks.umt.edu/wildbio_pubs/13

This Article is brought to you for free and open access by the Wildlife Biology at ScholarWorks at University of Montana. It has been accepted for inclusion in Wildlife Biology Faculty Publications by an authorized administrator of ScholarWorks at University of Montana. For more information, please contact scholarworks@mso.umt.edu. 
Authors

J. J. Tewksbury, L. Garner, S. Garner, J. D. Lloyd, V. Saab, and Thomas E. Martin

This article is available at ScholarWorks at University of Montana: https://scholarworks.umt.edu/wildbio_pubs/13 


\title{
TESTS OF LANDSCAPE INFLUENCE: NEST PREDATION AND BROOD PARASITISM IN FRAGMENTED ECOSYSTEMS
}

\author{
Joshua J. Tewksbury, ${ }^{1,7}$ Lindy Garner, ${ }^{2}$ Shannon Garner, ${ }^{3}$ John D. Lloyd,${ }^{4}$ Victoria SaAB,${ }^{5}$ \\ AND Thomas E. MARTin ${ }^{6}$ \\ ${ }^{1}$ Department of Biology, University of Washington, 106 Kincaid Hall, Box 351800, Seattle, Washington 98195-1800 USA \\ ${ }^{2}$ U.S. Fish and Wildlife Service, North Louisiana Refuges Complex, Farmerville, Louisiana 71241 USA \\ 32693 Ruggs Bluff Road, Downsville, Louisiana 71234 USA \\ ${ }^{4}$ Ecostudies Institute, 22345 South Poplar Road, Estacata, Oregon 97032 USA \\ ${ }^{5}$ USDA Forest Service, Rocky Mountain Research Station, 1648 South 7th Avenue, MSU Campus, \\ Bozeman, Montana 59717-2780 USA \\ ${ }^{6}$ USGS Montana Cooperative Wildlife Research Unit, University of Montana, Missoula, Montana 59812 USA
}

\begin{abstract}
The effects of landscape fragmentation on nest predation and brood parasitism, the two primary causes of avian reproductive failure, have been difficult to generalize across landscapes, yet few studies have clearly considered the context and spatial scale of fragmentation. Working in two river systems fragmented by agricultural and rural-housing development, we tracked nesting success and brood parasitism in $>2500$ bird nests in 38 patches of deciduous riparian woodland. Patches on both river systems were embedded in one of two local contexts (buffered from agriculture by coniferous forest, or adjacent to agriculture), but the abundance of agriculture and human habitation within $1 \mathrm{~km}$ of each patch was highly variable. We examined evidence for three models of landscape effects on nest predation based on (1) the relative importance of generalist agricultural nest predators, (2) predators associated with the natural habitats typically removed by agricultural development, or (3) an additive combination of these two predator communities. We found strong support for an additive predation model in which landscape features affect nest predation differently at different spatial scales. Riparian habitat with forest buffers had higher nest predation rates than sites adjacent to agriculture, but nest predation also increased with increasing agriculture in the larger landscape surrounding each site. These results suggest that predators living in remnant woodland buffers, as well as generalist nest predators associated with agriculture, affect nest predation rates, but they appear to respond at different spatial scales. Brood parasitism, in contrast, was unrelated to agricultural abundance on the landscape, but showed a strong nonlinear relationship with farm and house density, indicating a critical point at which increased human habitat causes increased brood parasitism. Accurate predictions regarding landscape effects on nest predation and brood parasitism will require an increased appreciation of the multiple scales at which landscape components influence predator and parasite behavior.
\end{abstract}

Key words: brood parasitism; buffer; Dendroica petechia; fragmentation; nest predation; riparian woodlands.

\section{INTRODUCTION}

Nest predation and brood parasitism are the primary sources of nest failure for most bird species (Martin 1992, Schmidt and Whelan 1999) and both are heavily influenced by landscape composition and structure (Robinson et al. 1995, Tewksbury et al. 1998, Kurki et al. 2000). Despite this, broadly generalizable patterns relating landscape features with nest predation and brood parasitism are lacking, and our ability to make predictions about the demographic consequences of landscape change is limited. For example, decreasing patch size, increasing edge habitat, and increasing land-

Manuscript received 26 November 2004; revised 13 June 2005; accepted 7 September 2005. Corresponding Editor: J. R. Walters.

${ }^{7}$ E-mail: tewksjj@u.washington.edu scape fragmentation were all once thought to increase the risk of nest predation and brood parasitism, but these effects now appear to be conditional on the types of habitat dominating the landscape at different scales (Donovan et al. 1997, Chalfoun et al. 2002, Stephens et al. 2004). Such conditional effects may arise because predators and parasites respond differently to fragmentation (Donovan et al. 1997, Tewksbury et al. 1998) and because different nest predators may respond to fragmentation at different scales, and in different ways (Andren 1992, Kurki et al. 2000, Chalfoun et al. 2002, Marzluff et al. 2004). Consideration of models that allow for such complex responses across scales might considerably advance our understanding of landscape effects on rates of nest predation and brood parasitism.

Here, we examined variation in rates of nest predation and brood parasitism by the Brown-headed 
Cowbird (Molothrus ater) in forest habitats on two river systems and relate this variation to landscape features proposed to influence the abundance of different nest predator guilds and brood parasites. To better understand the link between landscapes, nest predator communities, and nest predation, we describe and provide an empirical test of three models of nest predation on forest birds. The first model, called the Generalist Predation model, posits that nest predation in forest habitats is driven primarily by generalist nest predators associated with agricultural landscapes (Kurki et al. 2000, Chalfoun et al. 2002). Thus, reductions in agriculture on the landscape and the inclusion of naturalhabitat buffers around study sites should both decrease nest predation (Donovan et al. 1995, Robinson et al. 1995, Rodewald and Yahner 2001b, Miller et al. 2003).

These predictions, however, are contradicted by studies showing lower rates of nest predation in landscapes that have been extensively fragmented by agriculture (Tewksbury et al. 1998, Hannon and Cotterill 1998). These studies suggest that reduced predation on forest birds in more fragmented landscapes is caused by an associated reduction in predators that are dependent on forests and other natural habitats. In this scenario, predation rates are driven by forest and shrubland predators intrinsic to the natural habitats being removed. Paradoxically, under this Intrinsic Predation model, nest predation declines with increased agricultural development, and natural-habitat buffers around fragments should increase nest predation rates because of an associated increase in predators associated with these buffers.

To date, studies supporting each of these models have examined landscapes without much consideration for the scale or context of study sites within the landscape (Donovan et al. 1995, Robinson et al. 1995, Tewksbury et al. 1998, Hannon and Cotterill 1998, Rodewald and Yahner 2001a). Consequently, these studies cannot distinguish between habitat features that may be important locally, such as natural-habitat buffers, and features influencing predation rates at larger landscape scales. Without explicit consideration of landscape context, these studies are unable to address a third possibility: Nest predation rates at a given location may be a product of both forest-dwelling predators close to the study site and generalist agricultural predators acting at larger spatial scales. We call this the Additive Predation model. Under this model, increased agriculture at the landscape scale should increase nest predation rates regardless of local conditions, because nest predators associated with agriculture are often generalists by nature (raccoons, magpies), and are thus able to cross habitat buffers to access forest patches where nesting density is high (Andren 1992, Chalfoun et al. 2002). In contrast, the predators most often associated with forest and shrub habitats are squirrels, chipmunks, and other small mammals (Tewksbury et al. 1998, Hannon and Cotterill 1998, Chalfoun et al. 2002, but see Andren
1992). These predators often have greater habitat specificity than generalist agricultural predators, and are thus more likely to influence predation rates when these habitats are directly adjacent to habitats under study. Thus, the Additive Predation model predicts that nest predation rates will be highest in habitat patches embedded within agricultural landscapes surrounded by buffers of natural habitat.

Efforts to predict variation in rates of brood parasitism by the Brown-headed Cowbird, a generalist brood parasite, have also been stymied by a failure to identify causal links between landscape conditions and rates of brood parasitism. For example, the most common factor used to predict brood parasitism by cowbirds at broad spatial scales is forest cover, but relationships between parasitism and forest cover have been highly variable. A number of studies in North America have reported strong negative correlations between brood parasitism and forest cover (Donovan et al. 1995, Robinson et al. 1995, Thompson et al. 2000), others have found a positive correlation (Hahn and Hatfield 1995, Gustafson et al. 2002), and still others have found no relationship (Tewksbury et al. 1998). Such conflicting results suggest that forest cover is itself unlikely to be causally related to brood parasitism. Indeed, studies examining Brown-headed Cowbird movements and habitat use have found that the proximity and availability of high-quality foraging resources are much stronger predictors of cowbird abundance and parasitism rates than the amount of forest cover (Rothstein et al. 1984, Thompson 1994). Yet the identity of foraging resources may differ across habitats. In some systems, cowbirds favor short crop and pasture lands (Thompson 1994, Gates and Evans 1998, Goguen and Mathews 2000), suggesting that the abundance and distribution of agriculture should determine cowbirds parasitism rates, at least where these resources are limiting. In other systems, elements of rural habitation, including bird feeders and livestock feed lots, are primary feeding areas for cowbirds (Rothstein et al. 1984, Thompson 1994), suggesting that human habitation density, not agriculture, should predict parasitism (Tewksbury et al. 2002). In addition, foraging resources should constrain parasitism rates only when they limit the access of cowbirds to the pool of available nests. Where these resources are abundant, the ability of cowbirds to access all nests in a habitat should be constrained by other factors, such as territorial interactions among female cowbirds and alternative laying opportunities, not by the abundance of nearby feeding areas. This would result in a nonlinear association between foraging resources and cowbird parasitism.

Working in two river valleys in the interior western United States, we tested the relative abilities of the three predation models to explain variation in rates of nest predation. In addition, we tested the relative importance of agriculture and human habitation as primary landscape factors explaining variation in rates of 
brood parasitism by the Brown-headed Cowbird. Within each river system, we worked on multiple study sites that were either buffered by relatively unmodified forest or woodland, or directly adjacent to agricultural areas.

\section{Methods}

\section{Study sites and landscapes}

We monitored nesting success, nest predation, and brood parasitism on 22 sites on a $100-\mathrm{km}$ section of the South Fork of the Snake River, in eastern Idaho, USA (Saab 1999, Tewksbury et al. 2002) and on 16 sites along the Bitterroot River and its tributaries in the Bitterroot Valley, in western Montana, USA (Tewksbury et al. 1998). All study sites on both river systems were deciduous riparian communities, dominated by black cottonwood (Polulus trichocarpa), narrow-leaf cottonwood ( $P$. angustifolia), and quaking aspen ( $P$. tremuloides) (Tewksbury et al. 1998, Saab 1999).

In both river systems, study sites were embedded in one of two local contexts: unbuffered sites, where agricultural fields and row crops were directly adjacent to the river and riparian study sites $(n=8$ on the Bitterroot River, $n=9$ on the Snake River), and buffered sites, which were buffered from agriculture by $150-800 \mathrm{~m}$ of relatively unmodified forest or woodland (here called woodland buffers). On the Bitterroot River, buffered sites $(n=7)$ were located on tributaries, and buffers were of pine-fir forest (Tewksbury et al. 1998). On the Snake River, buffered sites $(n=8)$ were on the main river, but were separated from agriculture by Douglas fir (Pseudotsuga menziesii), juniper (Juniperous osteosperma), and sagebrush (Artemisia spp.), often growing on bluffs above the river (Saab 1999). Importantly, on both rivers, the amount of forest and agricultural development varied considerably around both buffered and unbuffered sites (see Results). This allowed us to separate changes in predation and parasitism associated with the presence of woodland buffers from changes attributable to differences in the amount of agriculture, human habitation, and forest on the larger landscapes surrounding each site. For more detailed descriptions of the locations of all study sites, see Tewksbury et al. (1998) and Saab (1999).

\section{Landscapes analysis}

We define the landscape of interest as all land within a $1 \mathrm{~km}$ radius circle centered on the study site. Landscapes of similar size have been shown to be strongly correlated with predation rates and avian community response on these river systems and elsewhere (Tewksbury et al. 1998, 2002, Saab 1999). We digitized land use patterns within each landscape into a GIS using aerial photographs, ortho-photo quadrat maps, and extensive ground surveys to determine the proportion of each local landscape made up of active agriculture (row crop and mixed pasture/row crop in both river systems), human habitation (primarily farms and country houses in both river systems), and natural vegetation. Natural upland vegetation was predominantly forest and woodland along both rivers, with Ponderosa pine (Pinus ponderosa) and Douglas fir communities predominating along the Bitterroot River, and Douglas fir, aspen, juniper, and sagebrush communities common along the Snake River.

\section{Nest monitoring and analysis}

We monitored a total of 2165 nests on the Snake River from 1992 through 1994, and a total of 2901 on the Bitterroot River from 1995 through 1998. All nests were monitored every 2-4 days to determine activity, fate, and parasitism status (presence of a cowbird egg). The same four open-cup nesting species were most common on both river systems: Yellow Warbler (Dendroica petechia), American Robin (Turdus migratorius), Black-headed Grosebeak (Pheucticus melanocephalus), and Cedar Waxwing (Bombycilla cedrorum).

We tested our three conceptual models of nest predation using two levels of analysis. In the first, our goal was to determine if daily nest predation rates (probability that a nest is depredated over a 24 -hour period) were consistently different between sites separated from agriculture by woodland buffers, and sites directly adjacent to agriculture. Buffered sites have, on average, less agriculture and more natural habitat within their landscapes than unbuffered sites (see Results). We pooled nesting attempts within each landscape condition, river system, and species, so that we could use the four most common open-cup nesting species on both river systems, and estimated daily nest survival using the Mayfield method (Mayfield 1975, Hensler and Nichols 1981). We tested the effect of local buffering by comparing Mayfield estimates from buffered and unbuffered sites on each river using Program Contrast (Sauer and Williams 1989), which creates a linear contrast of the survival rate estimates in each group and uses a chi-square statistic to test for homogeneity of rates. We used the Mayfield method for this simple categorical analysis to allow explicit comparisons with earlier work conducted on the Bitterroot River (Tewksbury et al. 1998), and because more advanced techniques produced similar results. We tested our overall hypotheses by contrasting survival estimates of all four species on both rivers from buffered and unbuffered sites. We also conducted the same test within each river system, and across river systems within each species.

To expand these results and explicitly test our three conceptual models, we took advantage of recent advances in information theoretic approaches that allow more robust and nuanced analyses of survival data (Burnham and Anderson 2002, Dinsmore et al. 2002, Shaffer 2004), and we examined nesting success using landscape data from each individual study site. We re- 
stricted this analysis to Yellow Warblers, and to sites where at least 12 nesting attempts were monitored (25 sites). Yellow Warblers accounted for $60 \%$ of all nests monitored across the four most common species (see Results), and the other three species did not have sufficient nest numbers on individual study sites to warrant this analysis. We used the generalized linear modeling approach of Shaffer (2004) to examine the combined impact of buffers and landscape-level land use practices on daily nest predation rates. This approach allows direct tests of each of our three conceptual models across both river systems, using the most common species on both rivers. Logistic-exposure models were fit using PROC GENMOD (SAS Institute 2004), with a binomial response distribution and the link function defined as per Shaffer (2004). Prior to analysis, we developed a set of candidate models (Burnham and Anderson 2002) that allowed us to test each of our hypotheses and included variables likely to cause variation in nest predation. We included the following landscape variables for each study site in building our set of candidate models: buffering (buffered vs. unbuffered); percentage of each $1 \mathrm{~km}$ radius landscape in active agriculture (arcsine-transformed to normalize percentage data); and percentage of each $1 \mathrm{~km}$ radius landscape in intact natural habitats, such as coniferous forest and shrubland (also arcsine-transformed). These three variables allow us to test each of our conceptual models. We also coded data from each river system with a unique dummy variable to test for differences between river systems unrelated to our landscape variables, giving us a measure of the generality of our results. Finally, we included nest age and the date of nest initiation as individual nest covariates in all models, as they both appear to commonly affect nest predation rates (Peak et al. 2004).

We evaluated a candidate set of nine a priori models (see Table 1), based on combinations of the variables identified above, which we believed could reasonably explain variation in nest predation rates. We evaluated the degree of support for each model using Akaike's Information Criterion (AIC; Akaike 1973). The best model was selected by judging the degree of support as measured by $\mathrm{AIC}_{\mathrm{c}}$ (AIC corrected for small sample size; Burnham and Anderson 2002) and normalized Akaike weights. Models with $\Delta \mathrm{AIC}_{\mathrm{c}} \leq 2$ were considered to have substantial support, whereas models with $\Delta \mathrm{AIC}_{\mathrm{c}} \geq 4$ were considered to have little to no empirical support (Burnham and Anderson 2001). Goodness of fit of the global model was evaluated using the decile method of Hosmer and Lemeshow (2000). We used the best-supported model to estimate daily survival rate, and used this estimate of daily survival rate, raised to the number of days in the nesting cycle, to estimate nest success. Tests of our hypotheses were based largely on model-averaged parameter estimates.

We interpreted the strength of each model parameter by using odds ratios calculated from model-averaged coefficients and $95 \%$ confidence intervals based on unconditional standard errors (Burnham and Anderson 2002). In addition, we used the same technique to calculate model-averaged estimates of daily predation rate (DPR) for buffered and unbuffered sites, using the least squared means procedure from each model. Using model-averaged estimates allowed us to incorporate modelselection uncertainty, and provided a more robust indication of the effect of each variable on nest success (Burnham and Anderson 2001). We used odds ratios and model averaged DPRs rather than beta coefficients as the basis for inference, because of their more intuitive interpretation. Except where noted, we did not interpret odds ratios with confidence intervals overlapping one.

For analysis of landscape effects on parasitism frequency (the percentage of nests parasitized), we again focused on Yellow Warblers, as parasitism was determined on sufficient numbers of nests in both river systems for site-by-site analyses $(n=315$ on 8 sites on the Bitterroot River, $n=435$ nests on 11 sites on the Snake River). We conducted analyses parallel to our analyses of nest predation. Our first analysis uses Pearson chi-squared tests to examine differences in parasitism rates between rivers and between buffered and unbuffered sites (lumping all nests in each category). We then examined parasitism on individual study sites ( $n=19)$ using an information-theoretic approach to assess the importance of agriculture and human habitation on brood parasitism across rivers and buffering categories of individual sites. Visual inspection of the data suggested the presence of a strong nonlinear relationship between human habitation and parasitism rate, but no such nonlinear relationship for agriculture. We thus examined linear and nonlinear (exponential) candidate models for the effects of human habitation, and linear candidate models for the effects of agriculture. Each landscape factor was examined alone, with river effects, with buffer effects, and with river + buffer effects, for a total of 12 models. We evaluated models and parameters as for predation, using $\mathrm{AIC}_{\mathrm{c}}$ values, model-averaged parameter estimates, and 95\% confidence intervals. All analyses were performed using SigmaPlot 8.02 (SPSS 2000) and SPSS 10.0.5 (SPSS 1999).

\section{Results \\ Landscapes}

Natural habitats (mostly woodland) comprised 11$78 \%$ of land area within $1 \mathrm{~km}$ of study sites $(38 \% \pm$ $18 \%$ [mean $\pm \mathrm{SD}$ ], median $=40 \%$ ) and were more abundant around buffered sites $(52 \% \pm 13 \%)$ compared to sites without buffers $(26 \% \pm 13 \%)$. Agriculture composed $15-74 \%$ of landscapes $(37 \% \pm 15 \%$, median $=$ $31 \%$ ) and was more common around unbuffered sites $(44 \% \pm 16 \%)$ compared to buffered sites $(28 \% \pm 9 \%)$. Human habitations made up between $0 \%$ and $12 \%$ of 
these rural landscapes $(1.7 \% \pm 3.3 \%$, median $=0.47 \%)$ and were also more common around unbuffered sites $(2.9 \% \pm 4.1 \%)$ compared to buffered sites $(0.3 \% \pm$ $0.4 \%)$.

\section{Nest predation}

Our analyses considered a total of 2511 nesting attempts spread across the four species and two rivers under study. The majority of nests were of Yellow Warblers (1502 nests). Daily nest predation rates were significantly higher in buffered study sites compared to unbuffered study sites (Fig. 1). All species in both rivers showed the same trend, with consistently strong effects of buffers for Yellow Warblers (Mayfield $\chi^{2}=$ $15.0, P=0.0001$ ) and American Robins (Mayfield $\chi^{2}$ $=10.4, P=0.0013)$, the two species with the largest sample sizes. Cedar Waxwings also showed significantly higher nest predation in buffered sites (Mayfield $\left.\chi^{2}=5.9, P=0.015\right)$, while the Black-headed Grosbeak showed a similar pattern, but no significant effect when both rivers were considered (Mayfield $\chi^{2}=1.3, P=$ $0.25)$.

Our individual-site analysis of Yellow Warblers produced strong support for the Additive Predation model: Local woodland buffers and increased agriculture in the landscape as a whole both increased predation rates (Table 1, Fig. 2). The best-supported models confirmed the existence of additive effects associated with woodland and generalist predators (Table 1). Goodness-offit tests (Hosmer and Lemeshow 2000) indicated that the global model fit the observed data (both $\chi^{2}=5.3$, $P=0.73$ ). Model-averaged daily predation rates were much higher in buffered sites (DPRs, buffered $=0.068$ \pm 0.005 [mean $\pm \mathrm{SE}]$; unbuffered $=0.029 \pm 0.002$ ) and model-averaged odds ratios indicated a large increase in the odds of predation on buffered sites compared to unbuffered sites (Table 2). The amount of agriculture in the landscape was also positively correlated with nest predation rates: A $1 \%$ increase in the amount of agriculture in the landscape produced a $3.6 \%$ increase in the likelihood of nest predation (Table 2, Fig. 2). River effects were not supported (Tables 1 and 2 ), indicating that the additive effects of woodland buffers and agricultural use were consistent across rivers (Table 1). Independent of habitat features, the date on which a nest was initiated had a negative effect on the likelihood of survival, such that each day nest initiation was delayed resulted in a $2.28 \%$ decline in the probability of success. Estimates of daily predation mortality generated from the best-supported model further support the importance of both landscape and local conditions to rates of nest predation (Fig. 2).

\section{Brood parasitism}

Brood parasitism on Yellow Warblers was greater in unbuffered sites on both river systems (Fig. 3a). On the Bitterroot River, parasitism frequency was $60 \%$ higher on unbuffered sites when compared to buffered

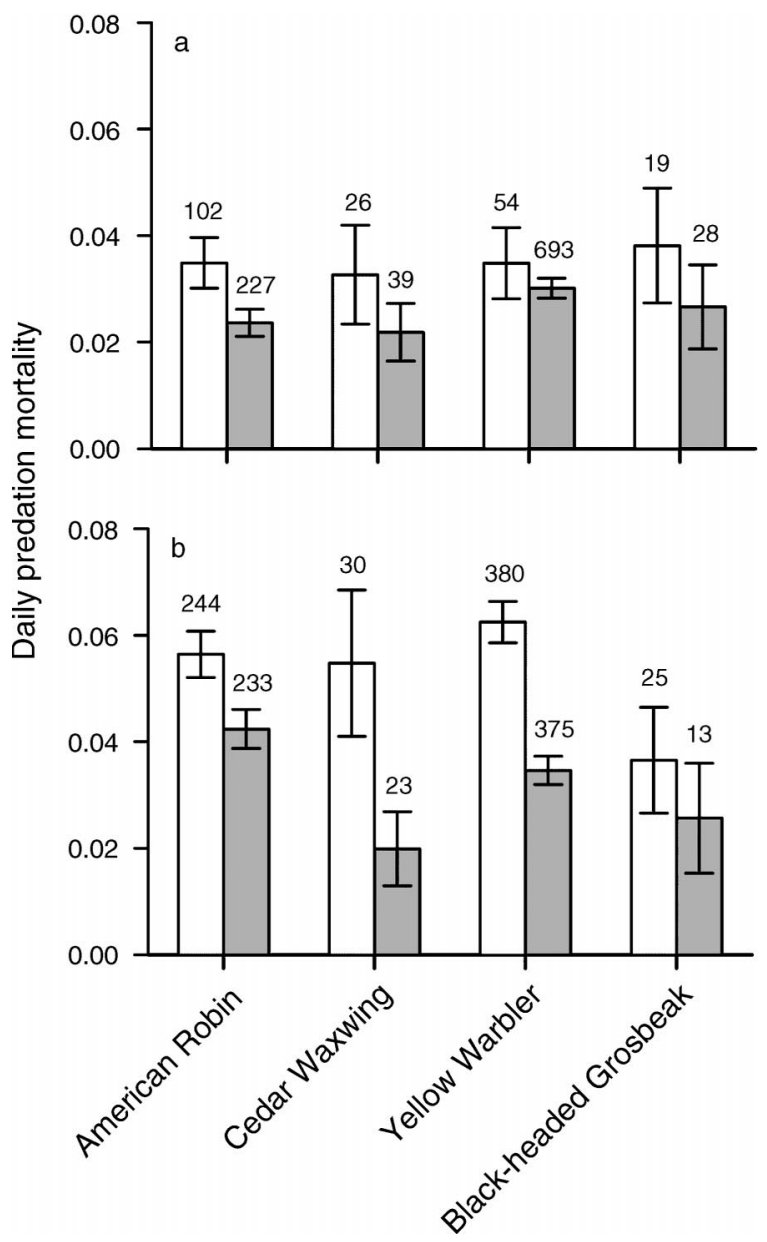

FIG. 1. Daily nest predation rates in (a) the Bitterroot River Valley and (b) the Snake River Valley for the four most common open-cup nesting species common to both river systems. Daily predation rates were higher in buffered sites (white) than in unbuffered sites (gray) for all species considered in both rivers (Mayfield $\chi^{2}=18.2, P<0.0001$ across species and rivers), and for each river system considered individually (Bitterroot River, Mayfield $\chi^{2}=3.9, P=0.047$; Snake River, Mayfield $\left.\chi^{2}=15.4, P=0.0001\right)$. Figures above the bars represent the number of nests monitored for each species under each landscape condition (buffered or unbuffered) on each river system.

sites $\left(\chi^{2}=7.02, P=0.008\right)$. On the Snake River, parasitism frequency was also much higher on unbuffered sites $\left(\chi^{2}=12.29, P=0.0005\right)$, though overall parasitism rates were low (Fig. 3a). Parasitism was more frequent in the Bitterroot River system than in the Snake River system in both buffered and unbuffered sites (buffered sites, $\chi^{2}=58, P<0.0005$; unbuffered sites, $\chi^{2}=161, P<0.0005$; Fig. 3 ). Comparing models of parasitism on the 19 individual sites, we found no support for the effect of agriculture $\left(\Delta \mathrm{AIC}_{\mathrm{c}}>23\right.$ for all models including agriculture; Fig. 3b, Table 3), but strong support for a nonlinear effect of human habitation (Fig. 3c, Table 3). The only models with any support all included an exponential increase in para- 
TABLE 1. Statistical models for Yellow Warbler nest predation, ranked by their level of support.

\begin{tabular}{lccc}
\hline \hline \multicolumn{1}{c}{ Model $\dagger$} & $K \neq$ & $\Delta_{i} \S$ & $w_{i} \|$ \\
\hline Buffer + agriculture + age + start date & 5 & 0.00 & 0.640 \\
Buffer + agriculture + river + age + start date & 6 & 1.80 & 0.261 \\
Buffer + agriculture + natural habitat + river + age + start date $($ global $)$ & 7 & 3.74 & 0.099 \\
\hline
\end{tabular}

$\dagger$ Other models included buffer + natural habitat + river + age + start date; buffer + natural habitat + age + start date; agriculture + age + start date; natural habitat + age + start date; river + age + start date; and constant predation. All of these models had $\Delta_{i}>19$, and $w_{i} \ll 0.0001$. As river was not significant, we did not run interaction models between river and agriculture and buffer.

$\ddagger$ The total number of estimable parameters (includes the intercept and $\Phi$ ).

$\S$ Change in $\mathrm{AIC}\left(\mathrm{AIC}_{\mathrm{c}} i-\operatorname{minAIC}\right)$.

\| Akaike weight $\left(\exp \left[-1 / 2 \Delta_{i}\right]\right)$; the likelihood of the model, given the data, normalized to sum to 1 across all models.

sitism with initial increases in human habitation, with a plateau of $62.8 \%$ parasitism occurring when human habitation makes up more than $2.5 \%$ of the landscape (Fig. 3c). We found no support for river or buffer effects (model averaged parameter estimates, river $=$ $1.04,95 \% \mathrm{CI}=-3.31-5.38$; buffer $=1.61,95 \% \mathrm{CI}=$ -2.70-5.91). Our global model including nonlinear human habitation effects indicated a good fit with the data $\left(F_{4,15}=79.6, P<0.0005\right)$.

\section{DISCUSSION}

Reported effects of fragmentation on nest predation and brood parasitism are often inconsistent across landscapes and communities (Stephens et al. 2004). In part, this is because nest predator communities and brood

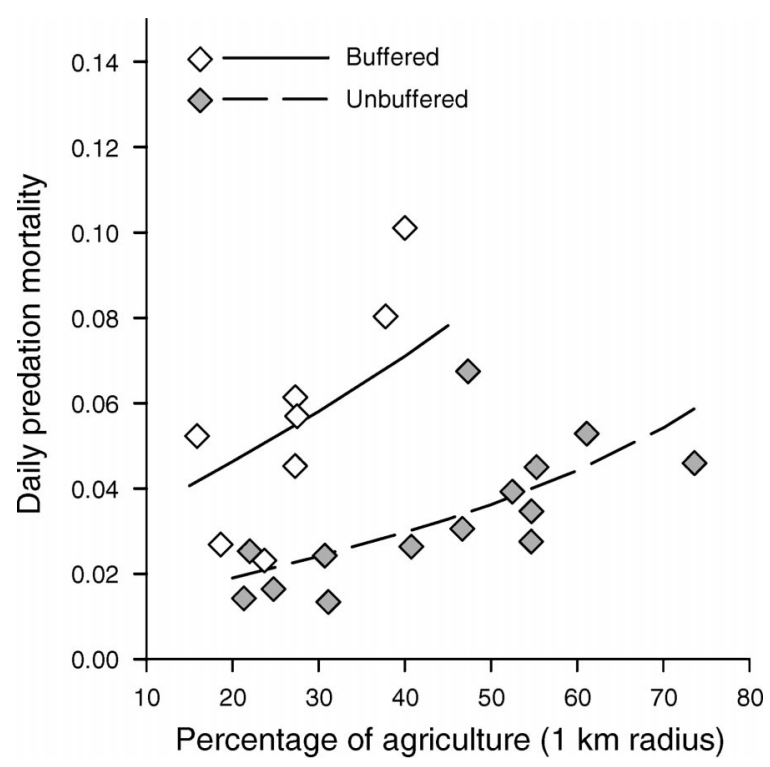

FIG. 2. Daily nest predation rates for Yellow Warblers as a function of the percentage of the local landscape devoted to agricultural development in buffered study sites (solid line) and unbuffered study sites (dashed line), from the best-supported model (Table 1). Mean predation on each study site shown for buffered sites (white symbols) and unbuffered sites (gray symbols) provides reference. Study site mean predation are least mean squares estimates for each site from a model including only site, nest age, and nest start date, and are included for illustration of site-specific trends. parasite behaviors are often oversimplified (Chalfoun et al. 2002). In addition, the landscapes under study are themselves often oversimplified (Mazerolle and Villard 1999). For example, many studies consider the amount of fragmentation without considering the types of land use that replace natural habitat (Rodewald and Yahner 2001a, Chalfoun et al. 2002). By explicitly considering the abundance and configuration of habitats and land use, rather than fragmentation per se, we show consistent patterns relating landscapes to both nest predation and brood parasitism across multiple western river systems.

\section{Nest predation}

Our initial analysis of nest predation shows the generally negative impact of woodland buffers in these fragmented landscapes (Fig. 1). These results, taken on their own, strongly suggest that nest predation should decrease with increased agricultural development, supporting the Intrinsic Predation model (Tewksbury et al. 1998) and calling into question the dominant paradigm that agricultural development causes increases in nest predation (Robinson et al. 1995, Donovan et al. 1995, Rodewald and Yahner 2001a). Our site-specific analysis, however, contradicts this interpretation. While buffers caused large increases in Yellow Warbler nest predation (Fig. 2), predation was also positively related to the amount of agricultural use, independent of the presence of buffers. These results support an additive model of nest predation in which predators associated with natural woodland habitats and predators associated with agriculture respond at different scales to habitat fragmentation (Fig. 2, Table 1), causing complex effects on predation rates. Our findings help to unify the Generalist Predation model (Robinson et al. 1995, Donovan et al. 1995, Rodewald and Yahner 2001) and the Intrinsic Predation model (Tewksbury et al. 1998, Hannon and Cotterill 1998) by explicitly acknowledging the effects of landscape configuration and the potential for mixing of predator communities.

Increases in nest predation in landscapes fragmented by agriculture are often attributed to increases in the abundance of generalist nest predators near habitat edges (Andren 1995, Donovan et al. 1997), in small forested fragments (Burke and Nol 2000), and in more- 
TABLE 2. Odds ratios, $95 \%$ confidence intervals, and percentage of change in odds ratios in daily predation mortality for Yellow Warblers.

\begin{tabular}{lccc}
\hline \hline \multicolumn{1}{c}{ Variable } & Odds ratio $\dagger$ & $95 \%$ CI & $\begin{array}{c}\text { Change in odds } \\
\text { ratio }(\%)\end{array}$ \\
\hline No buffer vs. buffer & 2.48 & $1.97-3.12$ & 147.88 \\
Percentage of agriculture & 1.04 & $1.02-1.05$ & 3.61 \\
Percentage of natural habitat & 1.0 & $0.98-1.01$ & -0.22 \\
Bitterroot vs. Snake Rivers & 0.98 & $0.81-1.18$ & 2.08 \\
Nest age & 1.02 & $0.99-1.03$ & 1.57 \\
Nest start date & 0.98 & $0.97-0.98$ & -2.28 \\
\hline
\end{tabular}

$\dagger$ Parameters were estimated using multi-model inference, giving the weighted average across all models that include the parameter $\left(x=\Sigma w_{i} 2_{i}\right)$.

fragmented landscapes (Andren 1992, Donovan et al. 1995, 1997, Robinson et al. 1995). What is less often appreciated is that predators that rely on relatively intact natural habitats, such as shrublands, woodlands, and forests, are also important sources of nest failure (Hannon and Cotterill 1998, Tewksbury et al. 1998). Thus, shifts in predator identity between fragmented and unfragmented landscapes may cause nonlinear or hierarchical relationships between predation rates and landscape structure (Andren 1995), such as the ones found here. The increase in Yellow Warbler nest predation associated with buffers (Fig. 2) appears to apply equally to other species (Fig. 1), suggesting that predators intrinsic to these natural habitats have a wideranging impact on nesting success in these habitats. We expect similarly broad results to apply to agricultural effects, as nest predators associated with agricultural areas are known generalists, preying on a wide range of bird nests (Andren 1992, Chalfoun et al. 2002; J. J. Tewksbury and L. Garner, unpublished data), and positive relationships between agricultural land use and predation rates are well documented in other systems (Donovan et al. 1995, Robinson et al. 1995, Rodewald and Yahner 2001b, Miller et al. 2003).

Like most river systems, both the Bitterroot and Snake River valleys represent modified landscapes: All of our study sites were within $1 \mathrm{~km}$ of some agriculture. The high nest predation rates observed in these habitats may be caused, in part, by depletion of top predators (Crooks and Soule 1999). Where top predators are rare or absent, generalist and opportunistic predators, such as squirrels, raccoons, and house cats, may be released from predation pressure (Crooks and Soule 1999, Schmidt 2003). Our results suggest that nest predation in riparian habitats is most severe where multiple predator communities mix. In these moderately developed rural, exurban, and suburban landscapes, woodland buffers may be large enough to support meso-predator populations, but not large enough to reduce predation from agricultural predators passing through these buffers. Unfortunately, many, if not most, large river systems in developed landscapes like those found in Europe and the United States likely fall into this category (Tewksbury et al. 2002).
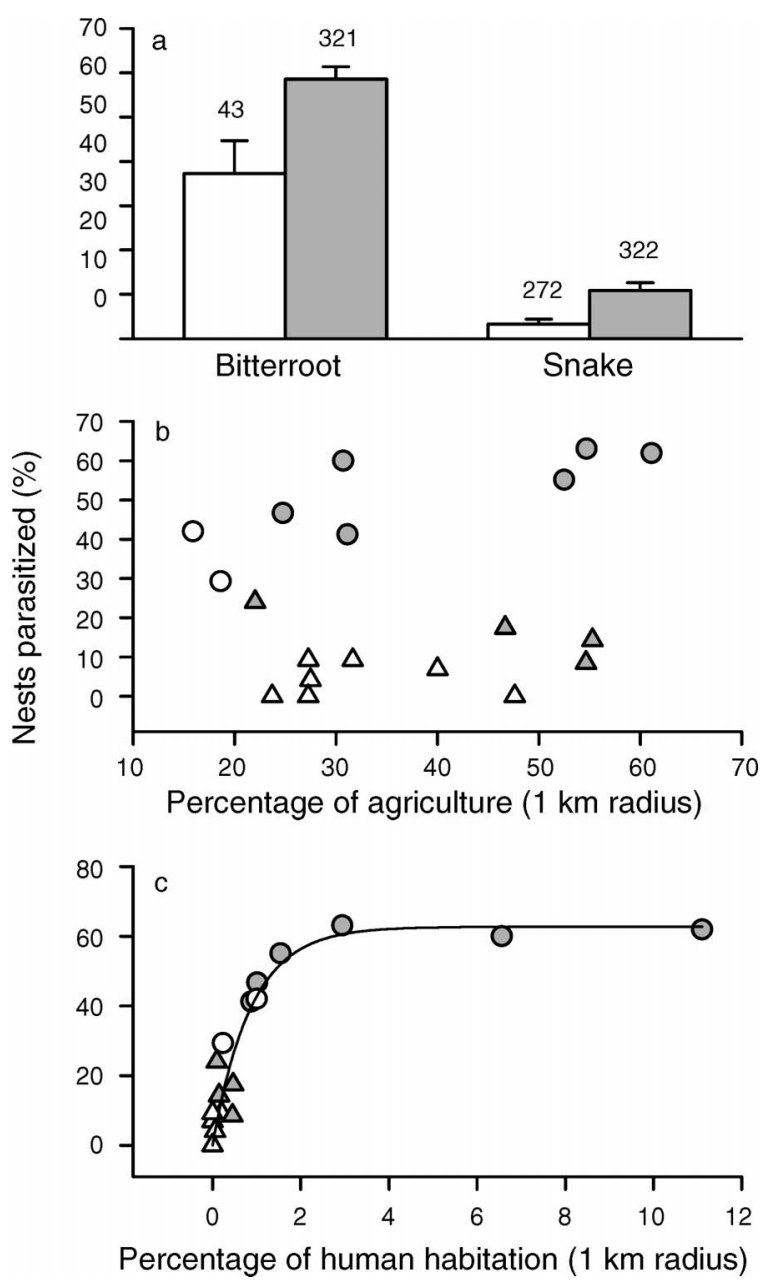

FIG. 3. Yellow Warbler parasitism frequency in buffered (white) and unbuffered (gray) study sites on the Bitterroot River (circles) and Snake River (triangles). (a) Overall rates of parasitism, with the number of nests for which parasitism status was determined indicated above each bar. Nest parasitism is shown as a function of the percentage of each landscape (b) devoted to agriculture and (c) devoted to human habitation. The regression line in (c) is from the best-supported model (Table 3), with parasitism modeled as an exponential function of human habitation density (percentage of nests parasitized $\left.=a \times\left[1-b^{\text {hab }}\right]\right)$. Model-averaged parameter estimates: $a=62.81 \pm 5.30($ mean $\pm \mathrm{SE}), 95 \% \mathrm{CI}$ $=52.42-73.19 ; b=0.32 \pm 0.08 ; 95 \% \mathrm{CI}=0.17-0.47$. 
TABLE 3. Statistical models for Yellow Warbler nest parasitism, ranked by their level of support.

\begin{tabular}{llll}
\hline \hline \multicolumn{1}{c}{ Model $\dagger$} & $K$ & \multicolumn{1}{c}{$\Delta_{i}$} & \multicolumn{1}{c}{$w_{i}$} \\
\hline$a \times\left(1-b^{\text {hab }}\right)$ & 3 & 0.0 & 0.649 \\
$a \times\left(1-b^{\text {hab }}\right)+$ buffer & 4 & 2.63 & 0.174 \\
$a \times\left(1-b^{\text {hab }}\right)+$ river & 4 & 3.02 & 0.143 \\
$a \times\left(1-b^{\text {hab }}\right)+$ buffer + river & 5 & 5.88 & 0.034 \\
\hline
\end{tabular}

$\uparrow$ The eight other models considered were parallel to those shown, with linear effects of human habitation (hab) instead of exponential (all with $\Delta_{i}>19$, and $w_{i} \ll 0.0001$ ) and with linear effects of agriculture (all with $\Delta_{i}>23$, and $w_{i} \ll$ $0.0001)$. We did not run interaction models, as agriculture was not a significant factor. See Table 1 for explanations of abbreviations.

While our results suggest a difference in the scale over which forest and agricultural predators affect nesting success, generalization of these results to other landscapes and other types of fragmentation must be done with caution, for two reasons. First, while we were able to clearly show the interactions between landscape character and natural-habitat buffers for Yellow Warblers, we did not experimentally impose or remove buffers, and thus, the landscape character around buffered and unbuffered sites was not identical (buffered sites tended to be surrounded by more forest, and less agriculture and human habitation) and the locations of these sites were determined by patterns of fragmentation, not by experimental design. Fortunately, we were able to separate the effects of agriculture and buffers because agricultural abundance on the landscape was highly variable for both buffered and unbuffered sites, with substantial overlap between buffered and unbuffered sites. Second, and perhaps more important, our understanding of the predator communities in these systems is incomplete. Previous research on the Bitterroot River has shown that red squirrels (Tamiasciurus hudsonicus), considered important nest predators in many forested landscapes (Cain et al. 2003, Martin and Joron 2003), are much more common on buffered study sites than unbuffered sites (Tewksbury et al. 1998). In addition, along both river systems, Black-billed Magpies (Pica hudsonia) are known nest predators (J. J. Tewksbury, L. Garner and S. Garner, unpublished data), and magpies are significantly more abundant at sites with more agriculture on both the Bitterroot and Snake Rivers (Tewksbury et al. 1998, 2002, Saab 1999). While it is reasonable to assume that magpies travel longer distances than squirrels and thus influence nest predation rates over greater distances, we do not yet know the relative contribution of each of these different predators to total predation rates, a critical component for predicting landscape impacts on predation rates in other areas (Heske et al. 2001). In addition, our predictive power will be greatly enhanced by a better understanding of the behavioral mechanisms linking specific predators to landscape features (Chalfoun et al. 2002).
Finally, the Additive Model of nest predation supported here suggests that different types of landscape fragmentation will have very different impacts on nest predation, because the predator communities replacing forest predators will depend on the landscapes created by fragmentation. Fragmentation due to logging should lead to very different predator communities than fragmentation due to agriculture. Understanding the differences in these types of disturbance should be a priority when landscapes are managed to protect diverse riparian bird communities.

\section{Brood parasitism}

The tight correlation between brood parasitism and human habitation density (Fig. 3c) corroborates behavioral work showing that cowbirds in these landscapes feed primarily at feed lots and bird feeders associated with houses and farms (Thompson 1994, Tewksbury et al. 1998). Thus, the density of human habitations appears to be closely linked to the availability of high-quality feeding resources. Where farms and houses were rare, small changes in the amount of human habitation were linked to large changes in parasitism rates. Where human habituation was more abundant ( $>2 \%$ of the land area), further increases had little or no effect on parasitism, indicating that factors unrelated to foraging opportunities, such as the availability and quality of laying opportunities (Barber and Martin 1997, Tewksbury et al. 1998, 1999), may limit parasitism in these circumstances.

Buffered landscapes and landscapes on the Snake River in general had lower levels of human habitation, and correspondingly low parasitism, than unbuffered sites or sites on the Bitterroot River in general, but without site-by-site sampling, parameterization of the nonlinear relationship between parasitism and humanhabitation density would not have been possible. When variation within each river system and buffer category were included, almost all variance in parasitism frequency between sites was attributable to human-habitation density, regardless of river or buffer.

From a management perspective, this general relationship allows direct predictions linking potential changes in land use to their likely impact on parasitism rates. The sensitivity of parasitism rates to human habitation where these features are rare indicates that small changes in land use in relatively pristine habitats, such as the removal of a single feedlot or pack-station, may have large impacts on parasitism rates, while even large changes in human-dominated landscapes are unlikely to affect parasitism. Because isolated houses and farms make up the leading edge of rural development (Miller et al. 2003), this variable may have strong predictive power across western landscapes. Importantly, where cowbirds forage on different resources, models will have to be amended to include these resources, but the nonlinear nature of the relationship should remain. 


\section{Conclusions}

Our ability to predict the effects of changes in landscapes on communities of interest will likely depend on our ability to uncover mechanistic relationships that are general enough to be applicable across systems. Our work suggests that multiple landscape features, operating at different spatial scales, may be needed to uncover such relationships. By working across study systems and incorporating landscape context, we were able to resolve perceived differences between competing models of landscape fragmentation effects. Further refinement of these relationships and greater predictive power will come from the identification of predators and the study of their behavior as it relates to manageable landscape features. Brood parasitism by the Brown-headed Cowbird provides an example: Here we were able to link brood parasitism, caused by a single species, to resources influencing the behavior of that species, and the result was a strong predictive relationship between brood-parasitism rates and humanhabitation density. Equally strong relationships might be found between individual predators and landscape features, but because predation is caused by multiple species responding to landscape fragmentation in different ways and at different scales, the resulting patterns will be more complex, and we might not expect simple relationships to predominate.

All of our results clearly point to a vanishing target for conservation efforts: relatively pristine riverine landscapes where human habitation and agriculture is minimal (Miller et al. 2003, Stephens et al. 2004). As riparian corridors are increasingly populated, and fertile river bottom land is used for agriculture (Miller et al. 2003), the protection of the diverse bird populations breeding in riparian habitat may increasingly depend on our ability to safeguard the remaining relatively intact stretches of riparian habitat.

\section{ACKNOWLEDGMENTS}

We thank all of the many technicians who participated in nesting surveys in both river systems. We also thank Andrew Van Eck, Dr. Jeffrey Walters, and two anonymous reviewers for comments on the manuscript. This project was supported in part by the USDA Forest Service, Bitterroot Ecosystem Management Research Project, Rocky Mountain Research Station (Missoula, Montana), and the National Science Foundation (IBN-990212).

\section{Literature Cited}

Akaike, H. 1973. Information theory as an extension of the maximum likelihood principle. Pages $267-281$ in B. N. Petrov and F. Csaki, editors. Second International Symposium on Information Theory, Akademiai Kiado, Budapest, Hungary.

Andren, H. 1992. Corvid density and nest predation in relation to forest fragmentation: a landscape perspective. Ecology 73:794-804.

Andren, H. 1995. Effects of landscape composition on predation rates at habitat edges. Pages 225-255 in L. Hanssen, L. L. Fahrig, and G. Merriam, editors. Mosaic landscapes and ecological processes. Chapman and Hall, London, UK.
Barber, D. R., and T. E. Martin. 1997. Influence of alternate host densities on Brown-headed Cowbird parasitism rates in Black-capped Vireos. Condor 99:595-604.

Burke, D. M., and E. Nol. 2000. Landscape and fragment size effects on reproductive success of forest-breeding birds in Ontario. Ecological Applications 10:1749-1761.

Burnham, K. P., and D. R. Anderson. 2001. Kullback-Leibler information as a basis for strong inference in ecological studies. Wildlife Research 28:111-119.

Burnham, K. P., and D. R. Anderson. 2002. Model selection and multimodel inference: a practical information-theoretic approach. Springer-Verlag, New York, New York, USA.

Cain, J. W., M. L. Morrison, and H. L. Bombay. 2003. Predator activity and nest success of Willow Flycatchers and Yellow Warblers. Journal of Wildlife Management 67(3): 600-610.

Chalfoun, A. D., F. R. Thompson, and M. J. Ratnaswamy. 2002. Nest predators and fragmentation: a review and meta-analysis. Conservation Biology 16:306-318.

Crooks, K. R., and M. E. Soule. 1999. Mesopredator release and avifaunal extinctions in a fragmented system. Nature 400:563-566.

Dinsmore, S. J., G. C. White, and F. L. Knopf. 2002. Advanced techniques for modeling avian nest survival. Ecology 83:3476-3488.

Donovan, T. M., P. W. Jones, E. M. Annand, and F. R. I. Thompson. 1997. Variation in local-scale edge effects: mechanisms and landscape context. Ecology 78:20642075.

Donovan, T. M., F. R. Thompson, III, J. Faaborg, and J. R. Probst. 1995. Reproductive success of migratory birds in habitat sources and sinks. Conservation Biology 9:13801395.

Gates, J. E., and D. R. Evans. 1998. Cowbirds breeding in the central Appalachians: spatial and temporal patterns and habitat selection. Ecological Applications 8:27-40.

Goguen, C. B., and N. E. Mathews. 2000. Local gradients of cowbird abundance and parasitism relative to livestock grazing in a western landscape. Conservation Biology 14: 1862-1869.

Gustafson, E. J., M. G. Knutson, G. J. Niemi, and M. Friberg. 2002. Evaluation of spatial models to predict vulnerability of forest birds to brood parasitism by cowbirds. Ecological Applications 12:412-426.

Hahn, D. C., and J. S. Hatfield. 1995. Parasitism at the landscape scale: cowbirds prefer forests. Conservation Biology 9:1415-1424.

Hannon, S. J., and S. E. Cotterill. 1998. Nest predation in aspen woodlots in an agricultural area in Alberta: the enemy from within. Auk 115:16-25.

Hensler, G. L., and J. D. Nichols. 1981. The Mayfield method of estimating nesting success: a model, estimators and simulation results. Wilson Bulletin 93:42-53.

Heske, E. J., S. K. Robinson, and J. D. Brawn. 2001. Nest predation and neotropical migrant songbirds: piecing together the fragments. Wildlife Society Bulletin 29:52-61.

Hosmer, D. W., and S. Lemeshow. 2000. Applied logistic regression. Second edition. Wiley InterScience, Wiley and Sons, New York, New York, USA.

Kurki, S., A. Nikula, P. Helle, and H. Linden. 2000. Landscape fragmentation and forest composition effects on grouse breeding success in boreal forests. Ecology 81: 1985-1997.

Martin, J. L., and M. Joron. 2003. Nest predation in forest birds: influence of predator type and predator's habitat quality. Oikos 102(3):641-653.

Martin, T. E. 1992. Breeding productivity considerations: what are the appropriate habitat features for management. Pages 455-473 in J. M. I. Hagan and D. W. Johnston, 
editors. Ecology and conservation of Neotropical migrant landbirds. Smithsonian Institution Press, Washington, D.C., USA.

Marzluff, J. M., J. J. Millspaugh, P. Hurvitz, and M. S. Handcock. 2004. Relating resources to a probabilistic measure of space use: forest fragments and Steller's Jays. Ecology 85:1411-1427.

Mayfield, H. F. 1975. Suggestions for calculating nest success. Wilson Bulletin 87:456-466.

Mazerolle, M. J., and M. A. Villard. 1999. Patch characteristics and landscape context as predictors of species presence and abundance: a review. Ecoscience 6:117-124.

Miller, J. R., J. A. Wiens, N. T. Hobbs, and D. M. Theobald. 2003. Effects of human settlement on bird communities in lowland riparian areas of Colorado (USA). Ecological Applications 13:1041-1059.

Peak, R. G., F. R. Thompson, and T. L. Shaffer. 2004. Factors affecting songbird nest survival in riparian forests in a Midwestern agricultural landscape. Auk 121:726-737.

Robinson, S. K., F. R. I. Thompson, T. M. Donovan, D. R. Whitehead, and J. Faaborg. 1995. Regional forest fragmentation and the nesting success of migratory birds. Science 267:1987-1990.

Rodewald, A. D., and R. H. Yahner. 2001a. Influence of landscape composition on avian community structure and associated mechanisms. Ecology 82:3493-3504.

Rodewald, A. D., and R. H. Yahner. 2001b. Avian nesting success in forested landscapes: influence of landscape composition, stand and nest-patch microhabitat, and biotic interactions. Auk 118:1018-1028.

Rothstein, S. I., J. Verner, and E. Stevens. 1984. Radio-tracking confirms a unique diurnal pattern of spatial occurrence in the parasitic Brown-headed Cowbird (Malothrus ater). Ecology 65:77-88.

Saab, V. 1999. Importance of spatial scale to habitat use by breeding birds in riparian forests: a hierarchical analysis. Ecological Applications 9:135-151.

SAS Institute. 2004. SAS software. Version 9.1. SAS Institute, Cary, North Carolina, USA.
Sauer, J. R., and B. K. Williams. 1989. Generalized procedures for testing hypotheses about survival or recovery rates. Journal of Wildlife Management 53:137-142.

Schmidt, K. A. 2003. Nest predation and population declines in Illinois songbirds: a case for mesopredator effects. Conservation Biology 17:1141-1150.

Schmidt, K. A., and C. Whelan. 1999. The relative impacts of nest predation and brood. Parasitism on seasonal fecundity in songbirds. Conservation Biology 13:46-57.

Shaffer, T. L. 2004. A unified approach to analyzing nest success. Auk 121:526-540.

SPSS. 1999. Statistical analysis software. Version 10.05, SPSS, Chicago, Illinois, USA.

SPSS. 2000. Sigmaplot 2000 for Windows. Version 6.0. SPSS, Chicago, Illinois, USA.

Stephens, S. E., D. N. Koons, J. J. Rotella, and D. W. Willey. 2004. Effects of habitat fragmentation on avian nesting success: a review of the evidence at multiple spatial scales. Biological Conservation 115:101-110.

Tewksbury, J. J., A. B. Black, N. Nur, V. Saab, B. L. Logan, and D. S. Dobkin. 2002. Effects of anthropogenic fragmentation and livestock grazing on western riparian bird communities. Studies in Avian Biology 25:158-202.

Tewksbury, J. J., S. J. Hejl, and T. E. Martin. 1998. Habitat fragmentation in a Western landscape: breeding productivity does not decline with increasing fragmentation. Ecology 79:2890-2903.

Tewksbury, J. J., T. E. Martin, S. J. Hejl, T. S. Redman, and F. J. Wheeler. 1999. Cowbirds in a western valley: effects of landscape structure, vegetation and host density. Studies in Avian Biology 18:23-33.

Thompson, F. R. I. 1994. Temporal and spatial patterns of breeding Brown-headed Cowbirds in the Midwestern United States. Auk 111:979-990.

Thompson, F. R. I., S. K. Robinson, T. M. Donovan, J. Faaborg, D. Whitehead, and D. R. Larson. 2000. Biogeographic, landscape, and local factors affecting parasitism levels. Pages 271-279 in J. N. M. Smith, T. L. Cooke, S. I. Rothstein, S. K. Robinson, and S. G. Sealy, editors. Ecology and management of cowbirds and their hosts. University of Texas Press, Austin, Texas, USA. 